\title{
Electric Permittivity of Vacuum
}

National Cancer Institute

\section{Source}

National Cancer Institute. Electric Permittivity of Vacuum. NCI Thesaurus. Code C68789.

A constant of proportionality that exists between electric displacement and electric field intensity in a vacuum. This constant is equal to approximately $8.854187817 \times 10 \mathrm{E}-12$ farad per meter (F/m). 